\title{
Construction of Micropiles Using Pressure Techniques
}

\author{
Hussein Elarabi and Amin Ahmed Abbas Soorkty \\ Building and Road Research Institute, University of Khartoum, Khartoum 11111, Sudan
}

\begin{abstract}
This paper discusses the technique of casting concrete of micropiles with pressures and the consequence of comparisons with normal way of casting concrete (casting with gravity). Preliminary geotechnical studies have been made in specific area in Sudan to predict the soil parameters and then an experimental work has been done for an estimated number of micropiles with different diameters and different techniques of placing concrete with various amount of pressure. This study was carried out to learn the usefulness of this technique in the field of structural foundations in Sudan. Capacities of micropiles were compared in cases of non-pressure casting (normal way of casting concrete) and pressure casting. Through the results, it was found that the entry of pressure factor in the operation of casting concrete increases the capacities of micropiles. The increased value of ultimate load depends on the amount of pressure applied.
\end{abstract}

Key words: Micropile, load test, pressure casting.

\section{Introduction}

Micropiles are small diameter piles (less than 300 $\mathrm{mm}$ ) which can be installed in almost any type of ground where piles are required with design load ( $3 t$ to $500 \mathrm{t})$.

The first use of micropiles dates back to the early 1950s in Italy, where new methods of underpinning for existing structures were needed to restore structures and monuments damaged during World War II [1]. Dr. Fernando Lizzi (Dr. Lizzi was a civil engineer and technical director with the Italian specialty foundation contractor Fondedile) is commonly recognized as the inventor of micropiles in the form of the root or Palo-radice.

Micropiles currently are widely specified and used in all construction sectors worldwide.

Sudan is characterized by variable soil types with vast territory and broad climatic zoon, which reflects the needs to deal, studied with the soil when designing various foundations by searching for the means and good solutions. Micropiles technology can be one of these means, and in this research, field tests were done

Corresponding author: Hussein Elarabi, Dr., professor, research field: geotechnical engineering. E-mail: husseinelarabi@yahoo.com. for estimated number of micropiles to study the performance of micropiles in the field of structural foundations in Sudan focusing on the capacity of the micropiles, taking into account the mix commonly used in Sudan (4:2:1 mix gives minim compressive strength $f c u=30 \mathrm{~N} / \mathrm{mm}^{2}$ ), so the research attempts to study the effect of pouring concrete with amount of pressure on the capacity of the micropiles.

The research outcomes could be used for setting guidelines for using micropiles for structural support.

\section{Micropile Classification}

Micropiles are generally classified firstly according to design application and grouting method. The design application dictates the function of micropile while the grouting method defines the grout/ground bond capacity.

In the design application, there are two types of application [2]. The first type is that the micropile is directly loaded either axially or laterally and the pile reinforcement resists the majority of the applied load. Examples of such application are shown in Fig. 1. This type of pile is used to transfer structural loads to deeper, more competent or stable stratum and may be used to restrict the movement of the failure plane in slopes. The 


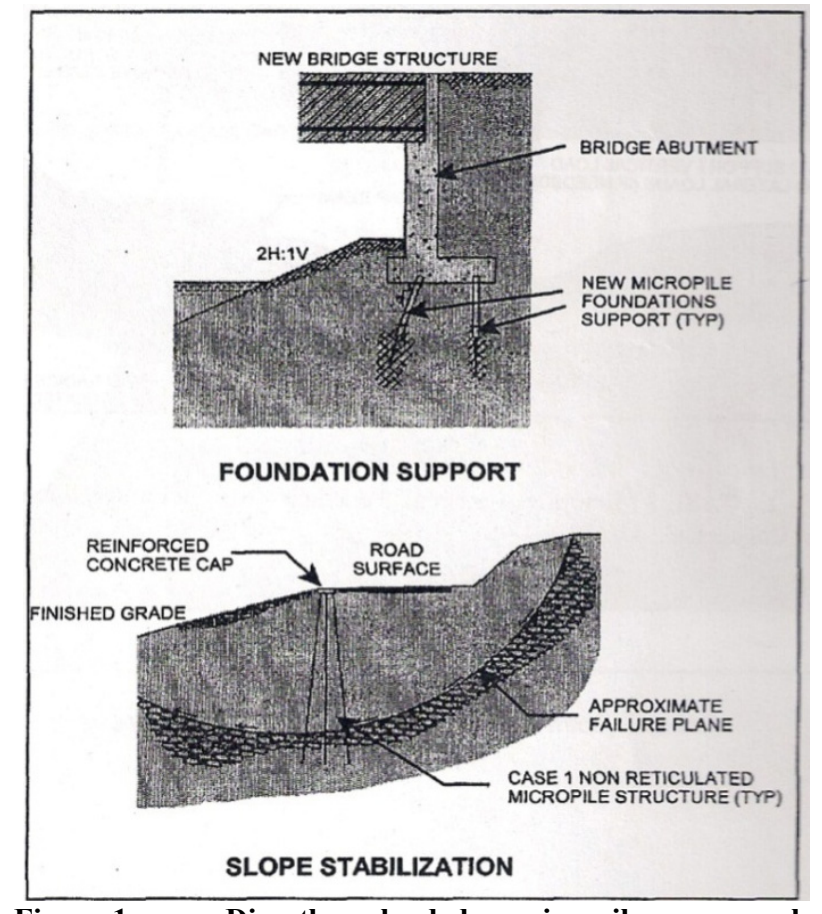

Fig. 1 Directly loaded micropiles example (FHWA-SA-97-070) [3].

loads are primarily resisted by the steel reinforcement structurally and by the grout/ground bond zone geotechnically.

Second type of design application is that the micropile reinforces the soil to make a reinforced soil composite that resists the applied load and is known as reticulated pile net work. This application of micropile serves to circumscribe and internally strengthen the reinforced soil composite [4].

The method of grouting is generally the most sensitive construction control over grout/ground bond capacity and varies directly with the grouting method. The second part of the micropile classification is based primarily on the method of placement and pressure under which grouting is used during construction [5].

\section{Experimental Work for Micropiles Constructed in Sudan}

\subsection{Soil Investigations}

\subsubsection{Laboratory Testing}

The soil where the field works have to be carried is identified and classified according to the British Standard BS 1377 with the USCS (Unified System for
Classifying Soils). The area of $20 \times 20 \mathrm{~m}^{2}$ in the land of B.R.R.I, U of K (Building and Road Research Institute, University of Khartoum) located in Soba, south of Khartoum, was used for carrying the experiments.

Soil tests were conducted on this area through drilling three boreholes with depths 15, 20 and $15 \mathrm{~m}$, respectively.

The laboratory tests performed included Atterberg limits, grain size distribution, triaxial compression, consolidation, specific gravity, moister content, permeability and SPT (standard penetration test)-result test.

\subsubsection{Soil Profile}

The boreholes drilled at the investigated area revealed that the soil profile consists of three layers. A layer of silty clay of low plasticity extended from surface to $5.0 \mathrm{~m}$. This layer was underlain by a layer of clayey sand which extends to the average of $14.0 \mathrm{~m}$. A layer of silty clay of high plasticity was encountered at $14.0 \mathrm{~m}$ and extended to the bottom of the profile.

\subsection{Preliminary Design of Micropiles for Testing} Program

The data used for the design are $f c u=30 \mathrm{~N} / \mathrm{mm}^{2}$ and minimum yield steel stress $f y=420 \mathrm{~N} / \mathrm{mm}^{2}$.

The description of the soil through which the bond length will be calculated is: hard, light brown, dry, silty clay of low plasticity with calcareous material.

From the summary of typical dbond (grout to ground bond) for preliminary micropile design and feasibility evaluation [6]:

(1) For micropile type $1 \mathrm{~A}$, $\partial$ bond $=50 \sim 120 \mathrm{kPa}$;

(2) For micropile type $1 \mathrm{~B}$, bbond $=70 \sim 190 \mathrm{kPa}$.

Accordingly, the soil test result will be $\partial$ bond $=120$ $\mathrm{kPa}$.

Design of micropile type (1A) is described as follows: the allowable compression load for the uncased length of a micropile according to FHWA (Federal Highway Administration) Design Guide Line is given as:

$P c$-allowable $=0.4 P c$-grout $\times A g+0.47 \times f y$-bar $\times$ Abar 
where, $A b a r=$ area of steel, $A g=$ gross section area of micropile, $P c=$ allowable compression load on micropile, fy-bar $=$ yield stress of steel bar.

We have four different diameters of piles: 10, 15, 20 and $25 \mathrm{~cm}$.

Area of cross section and steel is:

Ag10 $=7,857.14 \mathrm{~mm}^{2}$ use $3 \Phi 10$ Aast $=235.71 \mathrm{~mm}^{2}$, where Aast is total area of steel.

Ag15 $=17,678.57 \mathrm{~mm}^{2}$ use 4 Ф10 Aast $=314.28$ $\mathrm{mm}^{2}$;

Ag20 $=31,428.57 \mathrm{~mm}^{2}$ use $4 \Phi 12$ Aast $=452.57$ $\mathrm{mm}^{2}$;

Ag25 $=49,107.14 \mathrm{~mm}^{2}$ use 5Ф12 Aast $=565.71$ $\mathrm{mm}^{2}$.

Pc10-allowable $=0.4 \times 30 \times(7,857.14-235.71) \times$ $0.25+0.47 \times 420 \times 235.17 \times 0.5=46.129 \mathrm{kN}$;

Pc15-allowable $=83.112 \mathrm{kN}$;

Pc20-allowable $=137.596 \mathrm{kN}$;

$P c 25$-allowable $=201.46 \mathrm{kN}$.

Calculation of bond length is as follows: accordingly, allowable axial load - SLD (service load design) is as follows [7]:

$$
P G \text {-allowable }=(\partial \text { bond } / F S) \times \pi \times D b \times L b
$$

where,

$\partial$ bond $=$ grout to ground ultimate bond strength;

$F S=$ factor of safety applied to the ultimate bond strength;

$D b=$ diameter of drill hole;

$L b=$ bond length;

$P G$-allowable $=$ micropile geotechnical capacity;

$L b 10=(46.129 \times 2) /(3.14 \times 0.1 \times 120)=2.4 \mathrm{~m}$;

$L b 15=2.9 \mathrm{~m}$;

$L b 20=3.65 \mathrm{~m}$;

$L b 25=4.3 \mathrm{~m}$.

Load structural capacity is as follows: from FHWA Design Guide Line:

Pult-compresion $=(0.85$ Pc-grout $\times$ Agrout $)+$ (fy-bar $\times$ Abar) ]

where, Pult $=$ the ultimate load compression on micropile;

Pult10-compresion $=94 \mathrm{kN}$;

Pult15-compresion $=160 \mathrm{kN}$;
Pult20-compresion $=274 \mathrm{kN}$;

Pult25-compresion $=402 \mathrm{kN}$.

\subsection{Experimental Work}

\subsubsection{Descriptions}

Micropiles were divided in five groups (G1, G2, G3, G4, G5), each group containing four piles with different diameters $(D 10=10 \mathrm{~cm}, D 15=15 \mathrm{~cm}, D 20$ $=20 \mathrm{~cm}, D 25=25 \mathrm{~cm})$. All piles have the same length $(4 \mathrm{~m})$. The total number of micropiles is 20 .

\subsubsection{Drilling Process}

A drilling machine mounted on a truck has been used with a petroleum-fueled machine for drillings micropiles holes. The auger is a drilling device which includes a rotating helical screw blade called flighting to act as screw conveyor to remove the drilled out materials. The rotation of the blade causes the material to move out of the hole being drilled.

\subsubsection{Placing Concrete}

The concrete mix used for micropiles is $4: 2: 1$ as normal common mix in Sudan $\left(f c u=30 \mathrm{~N} / \mathrm{mm}^{2}\right)$.

Pouring concrete for G1 by gravity as normal (according to the Classifications Type 1A) but for G2 to G5, pressures of 2 bar to 8 bar $(1 \mathrm{bar}=0.1 \mathrm{MPa})$ were used (according to the Classifications Type 1B).

A pressure machine (air compression of 25 bars) was used. Pressures of 2, 4, 6 and 8 bar were applied in pouring concrete in the holes for G2, G3, G4 and G5, respectively (Table 1).

3.3.4 Methodology of Compression Load Testing

This compression test using reaction frame or kentledge system is undertaken on a test concurrent

Table 1 The amount of pressures applied of groups.

\begin{tabular}{lll}
\hline Groups & Pressure (bar) & Micropile type \\
\hline G1 & 0 & 1A \\
G2 & 2 & 1B \\
G3 & 4 & 1B \\
G4 & 6 & 1B \\
G5 & 8 & 1B \\
\hline
\end{tabular}

According to FHWA Guide Line, 1A is Micropile Case 1 (directly loaded), Type A (concrete placed under gravity); 1B is Micropile Case 1 (directly loaded), Type B (concrete placed under pressure $=5 \sim 10$ bar). 
with construction of the micropiling works as shown in Fig. 2. The test is used to validate the micropile design. In this case, the micropile is loaded to three times the design working load.

\subsubsection{Testing Procedures}

Details of different testing procedures can be found in many publications [8]. All methods cited in the literature are either stress-controlled which has been used for this experiments or strain-controlled. Controlled-stress method has been used with QML (quick maintained load) test [9].

In this procedure, $15 \%$ of design load is added at a time and held for $5 \mathrm{~min}$. The maximum load is equal to three times the design load. When the load is reached, unloading is then done with four equal decrements allowing $5 \mathrm{~min}$ between each two decrements. Typical time of load test is between $3 \mathrm{~h}$ to $5 \mathrm{~h}$.

This method has advantage of being fast but it cannot be used when the pile is installed in strata with significant creep properties because load may be shed from the sides to the base without changes in the applied load.

\subsection{The Result of the Experimental Work}

The results of the experimental work are shown in Table 2 .

\section{Discussions}

According to the result of experimental work, the increasing of the failure load due to entering the pressure factor in the casting concrete process is clear. This is evident in Figs. 3 and 4.

Fig. 4 shows that there is a visible difference in the failure load values of micropiles between the two cases of casting concrete with pressure and without pressure.

Placing concrete by pressure techniques increases the load capacity of micropile, as a result of increasing the friction force between the pile and surrounding soil. This apprears clearly in piles of small diameter compared to the same relatively large diameter.

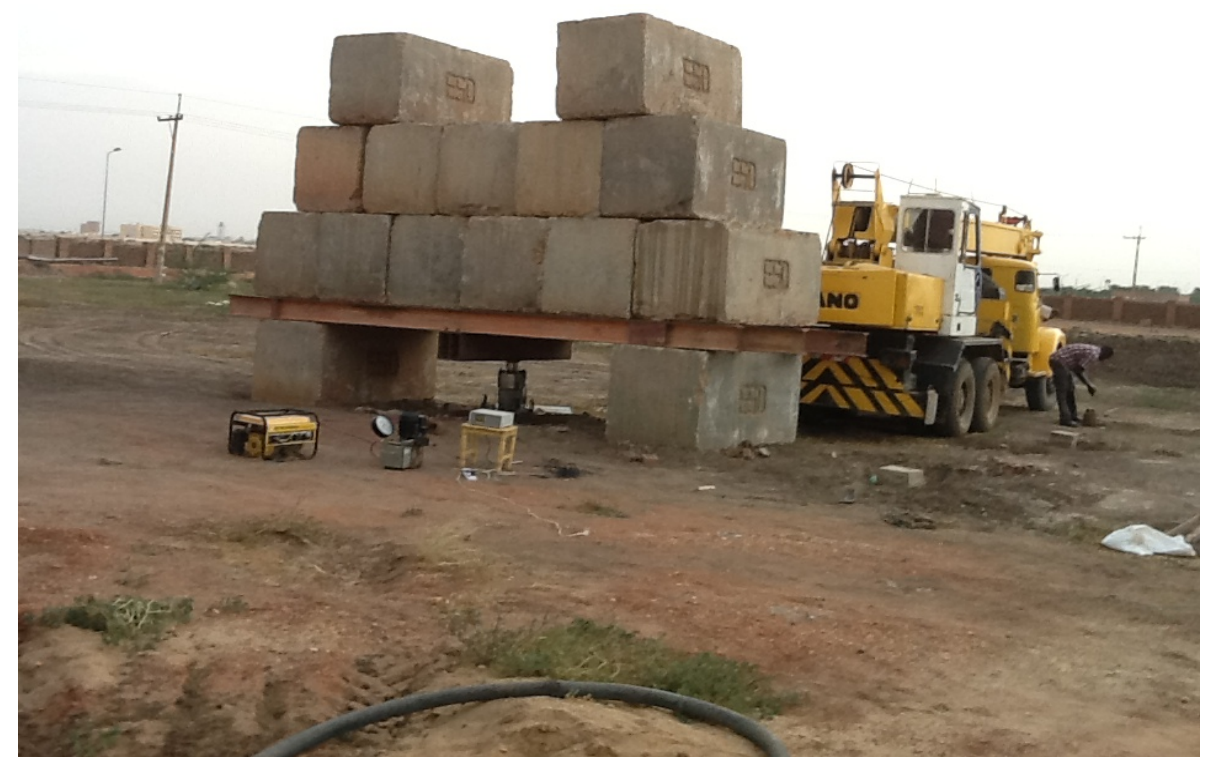

Fig. 2 Kentledge system of testing procedure in Soba site-Khartoum.

Table 2 The result of the experimental work, diameters against failure loads.

\begin{tabular}{llllll}
\hline$D($ diameter, $\mathrm{mm})$ & $\begin{array}{l}F(\text { failure load, } \mathrm{kN}) \\
\text { when } p \text { (pressure) }=0\end{array}$ & $\begin{array}{l}F(\mathrm{kN}) \text { when } \\
p=2 \text { bar }\end{array}$ & $\begin{array}{l}F(\mathrm{kN}) \text { when } \\
p=4 \text { bar }\end{array}$ & $\begin{array}{l}F(\mathrm{kN}) \text { when } \\
p=6 \text { bar }\end{array}$ & $\begin{array}{l}F(\mathrm{kN}) \text { when } \\
p=8 \text { bar }\end{array}$ \\
\hline 10 & 129.3 & 134.3 & 142.3 & 153.5 & 185.4 \\
15 & 235 & 262.5 & 292 & 298 & 345 \\
20 & 265 & 293 & 385 & 468 & 497.5 \\
25 & 445 & 534.5 & 553.3 & 557.3 & 565 \\
\hline
\end{tabular}




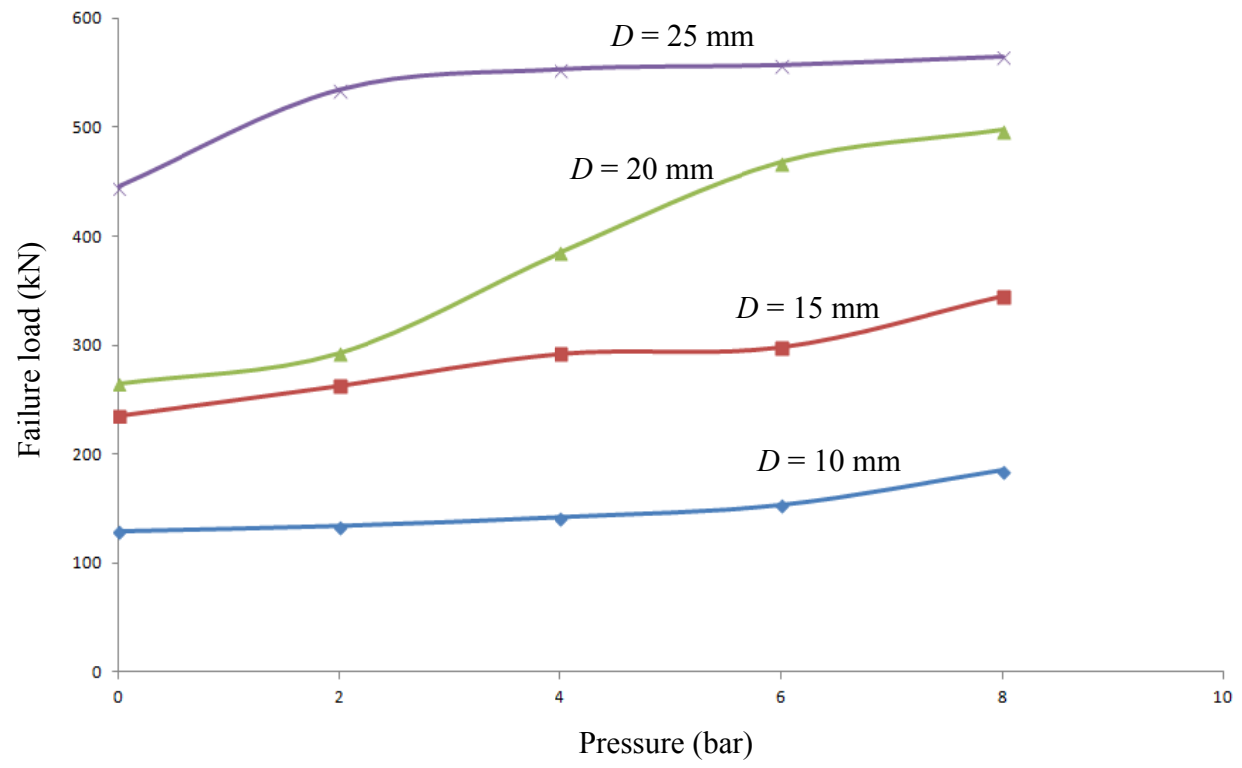

Fig. 3 Load vs. pressure curve (in case of different diameters of micropiles).

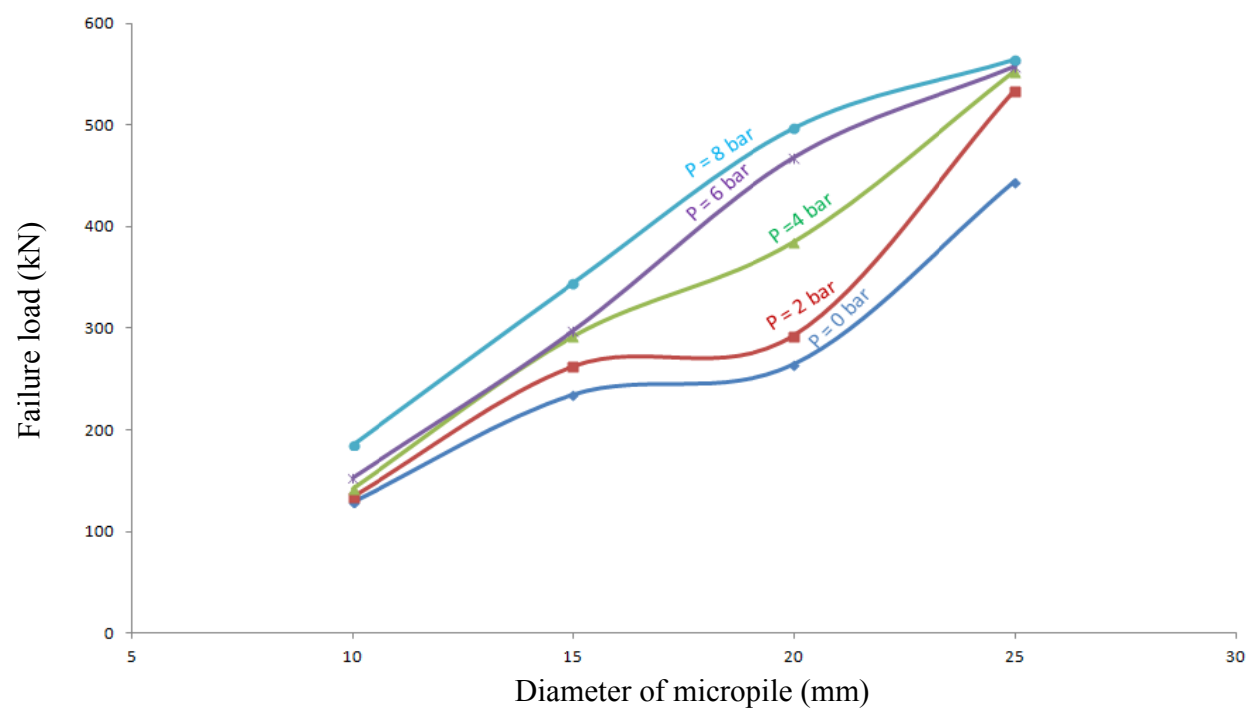

Fig. 4 Load vs. micropile diameter curves (in the case of different amount of pressures).

From the results, it can be observed that the maximum amount of pressure applied for placing concrete to micropile in this study is 8 bar. In case of placing concrete with amount greater than 8 bar, it is expected that more capacity of micropile can be produced.

\section{Conclusions}

Micropiles can be used as a normal foundation piles beside other known types in Sudan. There is an advantage of saving time and some time cost. It is a good solution for buildings in remote areas and also practical option to create cities light residential buildings. The price of micropile ranges globally $\$ 300 / \mathrm{m}^{3}[10]$.

Placing concrete by pressure techniques increases the load capacity of micropile as a result of increasing the friction force between the pile and surrounding soil.

The soil capacity can be controlled by increasing the strength of the soil in existing origin levels by using a 
pressure casting technique. The capacity of pile cast with pressure is equivalent to the capacity of pile of larger diameter cast without pressure. This is leading to reduced construction materials compared with normal piles. Micropile means less materials and labor so it can be used easier than other foundation types in places far away from the sources of materials which is suitable for a vast country like Sudan. More research is recommended to relate the micropile diameter to the amount of pressure added during casting concrete process.

\section{References}

[1] Lizzi, F. 1982. Static Restoration of Monuments. Genoa: Sagep Publisher.

[2] Wetman, A. 1981. "A Review of Micro Pile Types." Ground Engineering 5: 43-9.

[3] FHWA. 2000. Micropile Design and Construction Guidelines, Implementation Manual. US Department of Transportation Federal Highway Administration.

[4] Bruce, D. A., DiMillio, A. F., and Juran, I. 1997. "Micropiles: The State of Practice Part 1: Characteristics,
Definitions, and Classifications." Ground Improvement 1 (1): 25-35.

[5] Shong, I. L., Gue, F. C. C, and Partners Sdn Bhd, Kuala Lumpur. 2003. "Design \& Construction of Micropiles." Presented at Geotechnical Course for Pile Foundation Design and Construction, Ipoh.

[6] Bruce, D. A., Venetia, L. P., Cadden, A. W., and Sabatini, P. J. 2004. "Practical Advice for Foundation Design-Micropiles for Structural Support." In Proceedings of Geo-Frontiers 2005, 1-25.

[7] FHWA. 1997. Drilled and Grouted Micropiles State-of-Practice Review. Report No. FHWA-RD-96-016/019. United States Department of Transportation.

[8] ASTM D1143-81 Subsection 5.6/D1143M-07e1. 2013. Standard Test Methods for Deep Foundations under Axial Compressive Load. Geotechnical engineering standard.

[9] State of New York Department of Transportation, Geotechnical Engineering Bureau. 2007. Geotechnical Control Procedure, Static Pile Load Test Manual. Geotechnical Engineering Bureau.

[10] Chan, S. F., and Ting, W. H. 1996. "Micropile." In Proceedings of 12th South East Asian Geotechnical Conference, 93-9. 